\title{
On the Essentially Dynamic Nature of Concepts: Constant if incremental motion in conceptual spaces
}

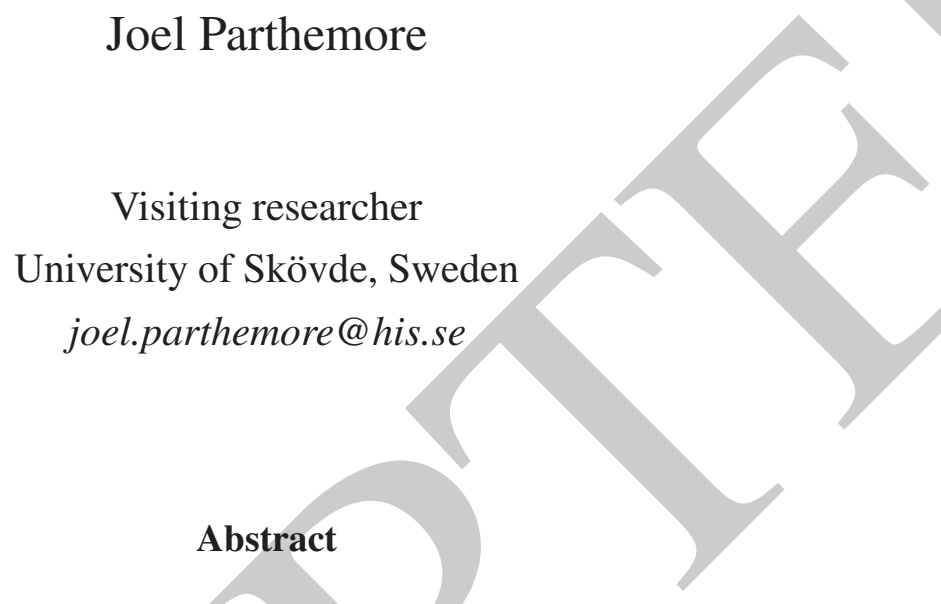

Concepts are the means by which we structure our understanding of the world and consequently the primary means by which we encounter it. It is commonly assumed that one of the essential characteristics of concepts - regardless of referent - is their stability, tending toward stasis; and, indeed, it can be hard to see how concepts can otherwise be systematic and productive, in the way they are conventionally taken to be. Even the question has been raised whether concepts can change; on some prominent accounts, they cannot. The Unified Conceptual Space Theory (UCST) - an extension of Conceptual Spaces Theory - makes the controversial claim that concepts not only are subject to change over an iterative lifecycle but that, at an underlying level, they are in a state of continuous motion; indeed, they must be to function as they do. Mere openness to change is not enough. Even the most seemingly fixed of concepts - mathematical concepts are the paradigm example - can be seen to evolve and continually be evolving as our understanding of mathematics evolves. UCST suggests that concepts possess an intrinsic tension that appears to present a contradiction: to be able to apply in more or less the same way across unboundedly many contexts (systematicity) and to be able to combine coherently with other concepts (productivity), they must be relatively stable; and yet, since each new application context is, in some nontrivial way, different from every previous context in ways that do not fit within neat conceptual boundaries, they must adapt each time to fit. In a physical world we have reason to view as ultimately one of fluidity, of processes and motion rather than stable entities, concepts should probably have a similar nature. 


\section{Introduction: How stable are our concepts, really?}

\subsection{Concepts and theories of concepts}

Theories of concepts are attempts, within cognitive science and philosophy of mind, to say what concepts are: i.e., what systematically structured thought is. They seek to lay out the ground rules for the organization of "higher-order" minds capable of stepping back from the present moment to consider it and its contents in light of moments past and moments yet to come. Among the contemporary theories being debated one finds Jerry Fodor's (1998) Informational Atomism, Jesse Prinz's (2004) Proxytypes Theory, Peter Gärdenfors' (2004) Conceptual Spaces Theory (CST) - and the author's own (Parthemore, 2013, 2011) Unified Conceptual Space Theory (UCST), an extension of CST. CST sees conceptual spaces as the analog to physical spaces, with a different space for each conceptual domain, its geometry determined by the integral dimensions of that domain ${ }^{1}$; while UCST attempts to show how all the different conceptual spaces described by CST come together in a single, unified "space of spaces" defined by the most basic integral dimensions common to all concepts. UCST comes with a toy software program for generating mind maps (Figure 1): visual descriptions of a given conceptual domain (Parthemore, 2011, ch. 8). ${ }^{2}$ The present paper is largely set within the framework of the latter two theories, though the claims that it makes should resonate well beyond.

For sake of working definition (one that should be acceptable within all the theories mentioned above), let us take concepts to be either the building blocks of systematically and productively structured thought or the abilities by which a certain class of agents - call them conceptual agents ${ }^{3}$ are able to engage cognitively with their environment in a systematically and productively structured fashion ${ }^{4}$. Concepts afford them a flexibility of response to that environment akin to that afforded by consciousness. ${ }^{5}$ Although various researchers have offered their largely if not strikingly similar lists of the defining properties of concepts (see e.g. Chrisley \& Parthemore 2007; Prinz 2004; Laurence \& Margolis 1999; Fodor 1998) - which generally if not universally include systematicity and productivity - I'm not aware of anyone listing stability or ultrastability among those properties. Nevertheless most researchers would appear to assume that concepts are, at least most of the time, stable ${ }^{6}$ entities -

\footnotetext{
1 ... In the case of the color space, they may be taken as hue, saturation, and brightness.

${ }^{2}$ Proxytypes Theory, Conceptual Spaces Theory, and the Unified Conceptual Space Theory are all derived from Prototype Theory, as developed by Eleanor Rosch (1999; 1975).

3 ... Or groups of those agents collectively. While some would distinguish between concepts for the individual and concepts for the group or society (see e.g. the discussion in Woodfield, 1994), I have argued (Parthemore, 2014b) that these represent the same phenomena, structured in essentially the same way, on different levels: i.e., individual, group, society, and possibly species.

${ }^{4}$ This longstanding debate, whether concepts are best understood as (abstract) objects or as abilities - is discussed in the opening pages of (Laurence \& Margolis, 1999) and at some length in (Parthemore, 2011, Ch. 2).

${ }^{5}$ For a discussion about the links between conceptual agency and consciousness, see (Parthemore, 2017), which argues that the two are really two sides of one coin.

${ }^{6}$ By "stable" I simply mean substantially resistant to change.
} 


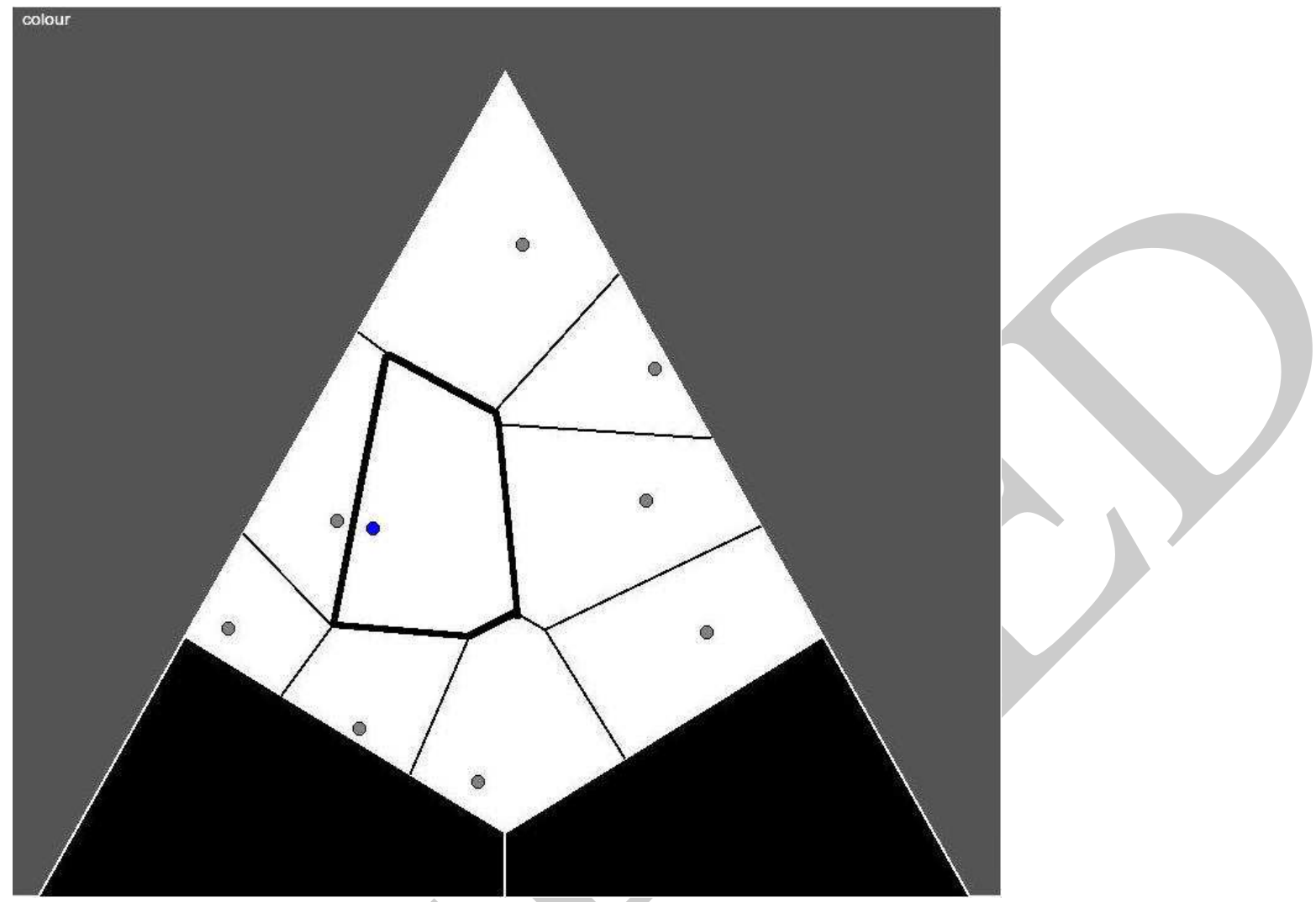

Figure 1: A partitioning of the space of properties (one of the three most general spaces within the UCST framework, along with the space of objects and the space of happenings). The concept "colour" (highlighted) stands in relation to such related properties as size, shape, and density. The person creating the mind map / partition can delve into the "colour" concept to subpartition it, or can add additional concepts to the space surrounding it. Of course, concepts (and so partitions) can also be deleted. (Illustration by the author.)

and some (notably Fodor, 1998) go so far as to argue that concepts do not and cannot change. ${ }^{7}$ If most researchers would allow that (at least most) concepts can change - within limits ${ }^{8}$ - they would also generally hold that, most of the time, concepts do not. Both the resistance to and boundaries of change are important: after all, what use would a concept of "grizzly bear" be if it applied to a type of mammal one day and a kitchen utensil the next? On reflection, it may seem as if this tending-toward-ultra-stable nature is obligatory on concepts, and that nothing more needs to be said.

${ }^{7}$ This is because, on his Informational Atomism account, concepts are mostly atomic (unstructured) entities defined solely by the things they track in the world. That is to say, Informational Atomism assumes some form of realist metaphysics. One could worry that, unless a realist metaphysics is presupposed a priori, that such an approach avoids the interesting story, which might seem (on an antirealist account, say, such as Immanuel Kant's transcendental idealism offers) to be the tangled relationship between concepts and their referents. That is to say, on such accounts, the interaction between concepts and referents is where the action is.

${ }^{8}$ Most researchers would allow that most concepts can change because most allow that beliefs are (partly) constitutive of concepts and not just that (as, so far as I know everyone - including Fodor - allows) concepts are constitutive of beliefs. Because beliefs can and do change - even if they may happen not to - therefore concepts can, and do, change. Note again though the frequently made distinction between individual agent's and societally shared concepts, whereby researchers are often much more willing to acknowledge change in the former than in the latter; see again (Woodfield, 1994). 


\subsection{Conceptual change}

Still - with a possible exception for mathematical concepts like parity and primeness, most researchers would, I think, accept the following:

Thesis 1. Concepts - to function as concepts - must be open to change.

This implies that any concepts that completely cease to be open to change are, metaphorically speaking - except perhaps for historical purposes $-\operatorname{dead}^{9}$. That is because those entities which concepts reflect are meant to be, if not changing, then open to change (with the possible exception of natural-kinds concepts, which I will come to presently.) Mathematical concepts are often thought of as particularly stable; but even concepts like parity conceivably could change if e.g. number theory were revised or expanded; after all, at no point can one comfortably announce that one has arrived at the "right" number theory.

The notion of conceptual "death" in turn implies the following, which I likewise take to be noncontroversial:

Thesis 2. Concepts may be seen to follow a life cycle of birth, maturation and (at least in certain cases) death.

Corrolary. The death of one concept is often the birth of another, or of several others.

Example. When the concept of phlogiston was discarded in the late 18th Century, the concept of oxidation may be seen to have taken its place. Although the "birth" of the oxidation concept preceded the "death" of the phlogiston concept (which lived on and lives on solely as a matter of historical interest), nevertheless the former may be seen as the natural heir of the latter.

This paper takes the far stronger position - strongly implied by UCST but, so far as I know, not defended elsewhere in print - that concepts are, by their nature, and from a critical and irreducible perspective, in a state of continuous (if often only incremental) change. The claim proceeds from what might be observed as a central (albeit seemingly paradoxical) tension in the nature of concepts. On the one hand, concepts - to function as concepts - must be both stable and general ("context free") enough to apply across unboundedly many contexts; systematicity and compositionality would seem to require if not outright presuppose this. On the other, concepts always are applied within specific contexts - each of which is, seemingly unavoidably, different in some substantive way from any that have gone before. That implies that concepts must be sensitive to context (i.e., "context sensitive"), adapting to fit each new context as needed: precisely Heraclitus' point when Plato quotes him (Cratylus, 402a) as saying "you cannot step into the same river twice". The following seems safe, again, to allow on most accounts:

\footnotetext{
${ }^{9} \mathrm{Cf}$. the concept of dead metaphor, where a metaphor (e.g., "safe haven") is argued not to function any longer as a metaphor.
} 
Thesis 3. Concepts must be just stable enough, but not too stable! Too stable or too dynamic and they cease to function as concepts.

The claims made by all three theses are mainly metaphysical rather than empirical in nature. They provide generally acceptable starting assumptions that, if they are good starting assumptions, will be explanatorily productive. If they are poor, they will prove awkward or lead to dead ends.

\subsection{From openness to change to obligation to change}

These thesis together are not, of course, sufficient to require continuous change. To get there requires two further ideas: first, that concepts are one thing when we self-reflect on them as concepts - in which case they typically appear as stable representations (often called mental representations); and logically quite another when we simply get on with possessing and employing them non-reflectively as, seemingly, most of the time we must do - in which case they might seem to be something else, something non-representational ${ }^{10}$ and action-based (for we are using them, not reflecting on them). ${ }^{11}$ Actions are, by nature, things in motion; and motion implies (if not requires) change. These two contrasting perspectives do a great deal, I think, to explain and resolve the debate over whether concepts are "really" representations or abilities. In truth, both perspectives are needed, and neither can be reduced to or otherwise reconciled with the other. If one allows these these two contrasting perspectives, then one will further allow that the apparent stability of concepts, when we reflect on them, need not and almost certainly does not reveal their full nature.

The second requisite idea, which I take to be largely uncontroversial (at least until considered in its full implications!) is that concepts are massively interconnected and - with care to avoid too close of a dictionary metaphor ${ }^{12}$ - interdefining. Not every agrees with such a view: Fodor, pointedly, views concepts (which he understands as atomic symbols) as strictly independent of one another, whereby

\footnotetext{
${ }^{10}$ Representations seem, to many enactive researchers among others, to imply if not outright require an agent to recognize them as representations: i.e., to take a representational stance toward them. People often use the term "representation" loosely, without ever bothering to define it. My longstanding inspiration on how $I$ wish to use the term comes from Inman Harvey: "The gun I reach for whenever I hear the word representation has this engraved on it: 'When $P$ is used by $Q$ to represent $R$ to $S$, who is $Q$ and who is $S$ ?'. If others have different criteria for what constitutes a representation, it is incumbent on them to make this explicit" (Harvey, 1992).

${ }^{11}$ For an extended discussion, see (Parthemore, 2011, pp. 110-112) and (Parthemore, 2013). Note the paradox here: the moment that we reflect on what it is like to possess and employ concepts non-reflectively, we bring them into the realm of self-reflection; in the very action of trying to catch them "in the act", we pull them out of that act and into the abstract realm of reflection. Reflecting on what is going on when we are not reflecting on what is going on threatens - like Russell's paradox - an unresolyable oscillation between two opposing views. As Zoltan Torey writes: “. . .we may take an object and just by focusing on it we notice almost at once that it (the content component) begins to recede and become overlaid by the nonthematic sensation that the whole experience is our own doing. However, this same sense of self-contribution, too, begins at once to fade, allowing the attention to swing back once more to the object in focus, from there to fade in turn, accentuating the self-sensation once more before the attentional pendulum swings back to the object again" Torey (2009, p. 112). Torey thinks this oscillation can be resolved by careful logical analysis and the underlying truth arrived at; I do not.

${ }^{12}$ Classical definitionist accounts are massively out of fashion, and for good reason, as both Fodor (1998) and Jesse Prinz (2004) are at pains to point out.
} 
“it's plausible prima facie that 'a' might refer to $a$ even if there are no other symbols" (Fodor, 1998, p. 54). ${ }^{13}$ The idea is that knowing about weddings or funerals may require, inter alia, knowing about flowers, which may require understanding what a rose is, which may require recognizing red, which may also be connected to one's understanding of fire hydrants, which may be connected with one's concept of dogs (at least in the popular American imagination), which requires understanding what a pet is, which is why - even if one has never heard or used the expression before - one knows immediately what Fodor means when he uses his favourite conceptual example of a pet fish. ${ }^{14}$ Fish is a type of seafood, which relates to sushi, which - if one has had a bad experience - may connect with one's concept of food poisoning. At no point does one reach the point where one may safely stop; the regress goes on as long as patience and cognitive resources allow. ${ }^{15}$ Think of concepts like a spider's web: pull on any one strand of the web, and the entire web vibrates, even if no one is there to observe it (or to observe it all). Alternatively, consider each new conceptually mediated experience like a pebble in a body of water, sending ripples to the farthest reaches - even if only some of those ripples are visible to the naked eye. If concepts and conceptual frameworks are massively connected in this way, then a change anywhere in the system will produce at least marginal movement throughout the system. To avoid this, one must argue either that concepts in general or some concepts or clusters of concepts in particular ${ }^{16}$ are more weakly connected: that is, that they are substantially context free, that they do not exist within a unified "space of spaces" such as UCST suggests.

The central claim of this paper, to be developed in the pages that follow, is that concepts - if they are to function as concepts at all - are, at least when we are not looking at them, moving targets. They are in a state of constant if incremental motion where each application of a concept (and we apply concepts constantly through our waking lives, along with no small part of our sleeping ones) causes ripples throughout the system. The claim further is that this should be true on every level on which one may talk about concepts - individual, group, society, even species - albeit on different time scales (Parthemore, 2014b). Even the most seemingly fixed of concepts - say, mathematical concepts of

\footnotetext{
${ }^{13}$ Note, too, that, for Fodor, concepts are lexical concepts (or compounds of lexical concepts), whereas I have consistently taken the view that concepts and language pull apart (another reason to avoid anything even smacking of definitionism): see e.g. (Parthemore, 2014b). Consequently I think - pace Fodor, but in keeping with the so-called animal concepts philosophers ( see e.g. Newen \& Bartels, 2007; Allen, 1999) - that pre-linguistic infants past a certain point in developmnent along with some number of non-human species possess conceptual agency.

${ }^{14}$ Fodor takes the pet fish as proof that concepts are not prototypes, on the argument that prototypes are compositional while concepts are not: for a pet fish is neither a prototypical pet nor a prototypical fish, never mind the intersection of the two. I prefer to take a different lesson: that concepts compose in a different way and along different paths from language, and that one does not arrive at the concept of pet fish simply by combining the lexical concept of pet with the lexical concept of fish. In short: an overly linguistic view on concepts seriously distorts one's view of them.

${ }^{15}$ Some years ago, I wrote a short-story writing environment for my master's thesis. The program invited the user to create a story world and populate it with characters, actions, objects, etc. A colleague, trying out the program, quickly found himself thirty levels down in recursion, describing what toilet paper is, to explain what a toilet is, to describe a spaceship, to explain something that described something that contained something else - all to create his first character, so he could write his first sentence.

${ }^{16}$ Natural kinds concepts, if they exist, would be the obvious example. Needless to say, the claims made here argue against them; see Section 3 below.
} 
primeness or parity - may be seen to evolve and continuously be evolving, for the individual and for society. Failure to be aware ${ }^{17}$ of change should not be taken as lack of change - not if the circumstantial evidence and logical arguments in favour of (continuous) change are sufficiently strong, as I will try to convince the reader they are.

\subsection{What I am not saying}

I am not claiming, as Heraclitus is commonly read, that "all is change and nothing stable" - which would reduce conceptual stability to at best a comforting illusion. This would be as wrong, I think, as to claim - per Parmenides in his famous poem - that nothing ever changes because change is illusion. Plato's solution was to adopt Parmenides' perspective for the world of his perfect Forms while allowing Heraclitus' perspective for the world we observe, where the Forms appear as but shadows on the cave wall. My own solution is to reject Plato's Forms in favour of Kant's noumena and to say that change and stability can co-exist simultaneously, in the same moment in the same entities in the same world, depending on whether one is stopping to reflect on the world or trying to catch that world simply in the act of being. There simply is no one fact of the matter. ${ }^{18}$

Neither am I - by arguing that concepts are constantly moving - denying the possibility of discontinuities: i.e., sudden, abrupt changes. Clearly, not all conceptual change is gradual, either for individuals (remember the moment you realized that nothing was hiding in the closet?) or societies or civilations (consider the conceptual changes set in motion by the discovery of microorganisms and pathogens). Particularly at the societal level, conceptual frameworks tend to resist change (beyond the necessary) for as long as they can, building up pressure at the boundary regions between one concept and another or one conceptual domain and another until a critical threshold is reached - at which point entire conceptual spaces may give way to make room for something new. ${ }^{19}$ A sudden insight may set a whole cascade of changes in motion.

Finally and perhaps most importantly, I am not claiming that the conceptual agent is, or even can be, aware of all the conceptual change - either within herself or in her society. The spider is aware of the slightest vibration in the furthest corner of the web, but the human observer loses track of the ripples in the water long before they die away. We should be particularly wary of what we conclude "must" logically be the case when we attempt to set our individual and collective (self-)reflections aside - if such a "perspective without a perspective" is even coherent! - and describe the world or the entities in it "as they really are". The claims put forth in this paper are not meant to be $a$

\footnotetext{
${ }^{17}$.. Which is to say, reflectively self-aware - if, in keeping with the phenomenologists, one distinguishes between "bare" conscious awareness (pre-reflective) and conscious awareness of conscious awareness (self-reflective); see e.g. (Gallagher, 2007).

${ }^{18}$ I wish to thank Sylvia Wenmackers (email) for reminding me of Heraclitus and Parmenides and Plato's response to them.

${ }^{19}$ For a visualization of this - with thanks again to Sylvia Wenmackers - see https://vimeo.com/231498722, accessed 2018-02-27.
} 
priori; rather, they are meant to hang together in a coherentist-like fashion, to facilitate explanations that might otherwise seem difficult or contrived. They provide no formal proof but only accumulate circumstantial evidence in their favour. A theory of concepts that allows concepts to be in continuous motion is, I think, a simpler, more elegant, more straightforward account than one that does not - as, again, I hope to convince the reader.

\subsection{The remainder of this chapter}

Section Two presents what I call the Illusion of Non-motion and argues via analogy that appearance of non-motion cannot be taken at face value. Sections Three and Four present the corresponding Argument from Motion and consider the role of abstraction in altering our view of that motion. Section Five discusses the theoretical and practical consequences of embracing the views expressed in this chapter. Section Six reviews the discussion and offers parting thoughts.

\section{The Illusion of Non-motion}

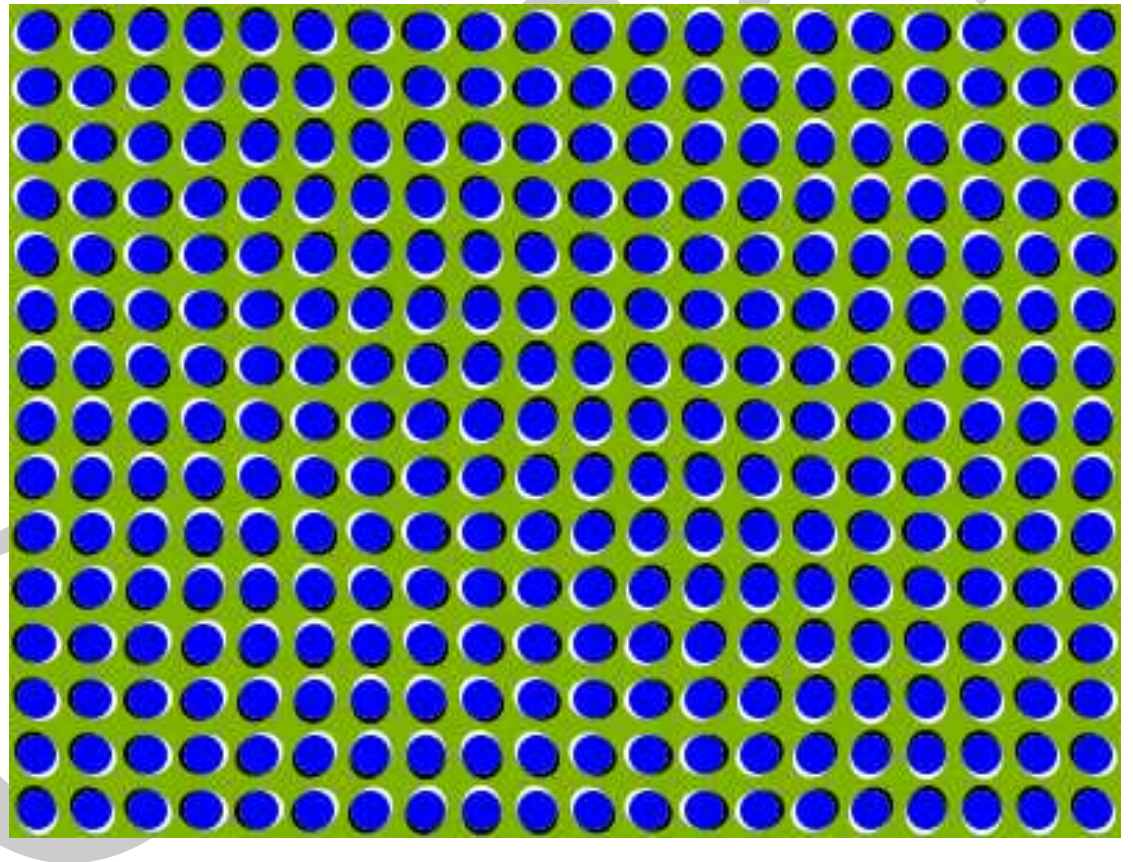

Figure 2: An illusion of motion: for most persons, the picture appears, when examined closely, to be waving back and forth like a flag in a slow breeze. Just as something can appear to be moving, even when rational consideration says that it's not (and cannot be); so, too, something can appear not to be moving even when rational consideration says that it is (and must be). Image reproduced from Wikimedia Commons: http://commons.wikimedia.org under the Creative Commons license.

Appearances can be deceiving. Just as apparent motion can be an illusion (Figure 2); so, too, can apparent non-motion. 
Plants are generally understood by lay persons - and often enough described by researchers - as non-moving, as opposed to animals (and microorganisms), which move around. But as any number of researchers have pointed out, the main difference in movement between plants and animals (beyond the existence, in most plants, of a root system, which fixes location and severely limits range of movement) is one of time scale. Plants appear not to move because they move, most of the time, on a much slower time scale than we do. So when we observe them naively, they appear motionless; when we change viewing perspective - most conveniently, by using time-lapse photography - they can be seen to move around quite actively, even purposefully, orienting themselves toward light (e.g., sunflowers) or water (the root system of many plants), or away from certain environmental irritants (e.g., Mimosa pudica); or capturing food, in the case of carniverous plants (e.g., Venus fly trap). ${ }^{20}$

Consider the first time, as a child, that you looked at a sample of pond water under a microscope. Again, a change of perspective takes something that at first appears inert and shows it to be full of motion. Or consider - likely with memories that evoke childhood - looking out the window of a fastmoving train at nearby vegetation. Intellectually you realize that the vegetation is rushing past you (or you past it) the same way as objects further in the distance; but because of its closeness, the "moving" vegetation (which is "moving" far more quickly than the background!) resolves into a stable, abstract pattern: a "fixed" tapestry of colour.

Finally, consider that, just as one can create a simple animation - an illusion of motion - by drawing a figure on a series of sheets of paper and then riffling through the sheets quickly, so that the figure may be seen to run, or skip, or jump, or play ball, and so on ${ }^{21}$; so, too, one can achieve a complementary effect by drawing a figure on a series of sheets of paper, where the entire figure is not to be found on any one of the sheets: that is, various sheets fill in details that others lack, or add details that are seen to disappear. By riffling through the sheets quickly, a stable image is formed that is not to be found on any one or another of the sheets. The figure can even shift position somewhat between sheets ("move around"), and yet the resulting image appears stable and motionless.

The seeming motionlessness of concepts arises not because, like the sunflower, they are moving too slow; nor because, like the vegetation viewed from the train, they are moving too fast. Neither is it because, like the pond water, we are failing to look closely enough (in that case, by using sufficient magnification) - because, no matter how intently we self-reflect on our concepts, whatever they happen to be concepts of (concrete or abstract objects, concrete or abstract actions or happenings, ${ }^{22}$ or properties of these things), stable representations are what we seem to find. Concepts are more like the partial figure on the sheets of paper, for concepts live in each instance of their application, even if what we recognize most readily as a concept is the seemingly stable image that emerges from consideration of all the instances of application, collectively: that is, that which abstracts away from all the instances

\footnotetext{
${ }^{20} \mathrm{~A}$ YouTube search on "plant movement" and "time-lapse" yields a number of striking videos.

${ }^{21}$ This is often an early exercise in teaching animation.

${ }^{22}$ Note, however, that there $i s$ an important difference between concrete and abstract entities when it comes to motion and change, which I will discuss in Section 3 below.
} 
of application. Concepts resemble the toys from fairy tales ${ }^{23}$ that only move (or only can move) when no one is watching; one recognizes their movement from the traces they leave behind. One looks, looks away, looks back again, and something has changed.

What is important to remember is that, if this chapter is correct, there is no one single fact of the matter about whether concepts are in continuous motion ${ }^{24}$; as the preceding discussion attempts to make clear, what counts as motion in the first place is often dependent on perspective: an irreducible and ineliminable characteristic of conscious, conceptual agents, who cannot help but take a perspetive. In his "Three-part invention", Douglas Hofstadter (2000, p. 30) relates the following Zen koan ${ }^{25}$ through his character Achilles:

Two monks were arguing about a flag. One said, "the flag is moving." The other said, "the wind is moving." The sixth patriarch, Zeno, happened to be passing by. He told them, "not the wind, not the flag; mind is moving."

\section{A world in motion}

The world around us as a whole - the world in which we find ourselves embedded and constantly (on some level) interacting (whether we are aware of doing so or not), the world from which we derive most if not all of our concepts, often strikes us in many ways as itself unchanging and unmoving. That, too - as many philosophers from Heraclitus onward, and many empirical researchers as well have claimed - is an illusion. The world, they say, is one of continuous motion and change, and it is only observation and reflection that appear to fix it in place: think of quantum mechanics (with its ineliminable role for the observer) and Schroedinger's cat.

Those things that seem most resistant to change do change, in time. On a geological time scale, lakes and entire river systems appear and disappear in the geological blink of an eye. Mountain chains like the Appalachian Mountains on the East Coast of North America are built up, worn down, built up again, and worn down again. Continents break or drift apart, ${ }^{26}$ or collide together.

But surely the Earth beneath my feet is fixed enough? ... It is, relative to my position on it. At the same time both of us are rotating around the Earth's axis at a speed (given my present latitude) of about $958 \mathrm{~km} / \mathrm{hr}^{27}$ while moving around the sun at a speed of about $107,279 \mathrm{~km} / \mathrm{hr}$. The solar system

23 ... Or the Weeping Angels from the British science-fiction series DR. WHO: statues of stone that literally come to life in the blink of an eye.

${ }^{24}$ This goes back to my point about the ongoing debate over whether concepts are (or are best understood as) representations or abilities, with each side assuming that one side or the other must be right. Rather, which perspective is primary and which secondary depends on circumstances, on the needs of the moment.

${ }^{25} \mathrm{~A}$ koan is a kind of mini-story used in Zen Buddhism to break people out of their conventional thinking habits and encourage spiritual awakening.

26 ... Which is why traces of the earlier Appalachian range are found on three continents.

${ }^{27}$ I would need to be standing at one of the poles for my rotational speed to be approximating to (though never actually reaching) zero. 
orbits the centre of the Milky Way galaxy at about 828,000 km/hr; once around takes close to a quarter of a billion years. ${ }^{28}$ The Milky Way galaxy itself, of course, is moving; on present course, it is set to collide with the Andromeda galaxy in four billion years.

Concepts - on just about any account and regardless of one's metaphysical starting point - are meant to reflect the world as accurately as possible. After all, they are the means by which we structure our understanding of the world; they are the instrument through which we approach and engage with it. If Heraclitus is right and the world is one of continuous motion and change then concepts, to reflect that world accurately, should be in continuous motion and change as well - otherwise, the presumed isomorphic relations between the two will quickly break down. (How well can the whole match if the parts do not?)

Unless one presupposes the existence of natural kinds ${ }^{29}$ - (unchanging and unchangeable) concepts that "carve nature at its joints" (to borrow Plato's famous phrase), picking out fixed regularities in the world ${ }^{30,31}$, then one will at least be open to the idea that concepts impose boundaries onto what are, from a conceptual perspective, underlying (fluid) continuities. That is to say, although the world severely constrains the categories we impose on it, it need not (and arguably should not) be seen as providing those categories ready made (Parthemore, 2011, pp. 58-59). Such a view gains credance from the widely reported phenomenon (in the psychology literature) of categorical perception, whereby a quantitatively evenly spaced set of stimuli (such as tones on a scale) are nevertheless perceived as falling into precise categories on one side or another of a binary divide ( $x$, not $x$ ): i.e., "stimuli related to a specific category are perceived as indistinguishable, whereas stimuli from a 'nearby' category are perceived to be entirely different.... In color perception, for example, different shades of green are perceived to be more similar than green and yellow even though the wavelength differences are no larger" (Gärdenfors \& Williams, 2001, p. 387; see also Harnad, 1990a). ${ }^{32}$

\footnotetext{
${ }^{28}$ These speeds are relative to our viewing perspective, of course. One of the striking consequences of Relativity Theory is that for every object in the universe, depending on one's vantage point, that object may be seen to be moving any speed at all from zero (rest) up till arbitrarily close to (though never reaching!) the speed of light: i.e., it's the relative speed that determines the observed speed; there is no simple fact of the matter what velocity something is traveling because there is no one, privileged perspective. From our vantage point on Earth, the most distant observable galaxies are moving away from us at speeds approaching the speed of light.

29 ... As does e.g. Brian Ellis (2005).

${ }^{30}$ The elements in the periodic table are frequently offered as examples.

${ }^{31}$ For all that natural kinds philosophers look to him for support, W.V. Quine may be read as putting the concept up to question: e.g. (1969, p. 13), "it is reasonable that our quality space should match our neighbor's, we being birds of a feather; and so the general trustworthiness of induction in the ostensive learning of words was a put-up job. To trust induction as a way of access to the truths of nature, on the other hand, is to suppose, more nearly, that our quality space matches that of the cosmos. The brute irrationality of our sense of similarity, its irrelevance to anything in logic and mathematics, offers little reason to expect that this sense is somehow in tune with the world - a world which, unlike language, we never made." Quine offers the hope that, in a "mature" science, the concept of kinds would disappear, and only the natural remain.

${ }^{32}$ There is, of course, no a priori reason to presuppose that categorical perception generalizes to all concepts; nevertheless, the widespread reporting of the phenomenon in different sensory modalities, along with the common argument from the empiricist tradition that concepts are grounded in perception (Harnad, 1990b) (or, more accurately perhaps, in sensorimotor engagements: see e.g. Gallese \& Lakoff, 2005; Parthemore, 2014c), raises that as a strong possibility.
} 
Take away natural kinds and we, as conceptual agents, become fluid motion in a world of fluid motion with no set boundaries - understanding both our world and ourselves as stable, well-bounded entities to the extent it suits our needs. We think of ourselves as the same person we were in our youth, but our ideas, beliefs, understandings change - most importantly, sometimes, our understanding of ourselves and what we see as our place in the world (for we are each, in an important way, the center of our own worlds). We remember those things that give us a sense of continuity and forget or disregard those things that seem quite alien to our present-day selves until something brings them back to mind - when suddenly we remember the child terrified of the shadows in the closet, maybe even are that child for a moment again, as Ray Bradbury (?) suggests in his short story, The thing at the top of the stairs. Of course this tension between being the same / not being the same is precisely what drove the ancient Greek debate and presented, for some, a paradox.

In discretizing the world, concepts impose a degree of stability onto its continuous motion, while never eliminating it entirely. They reify processes into objects, at the same time as abstracting away from their fluid nature, simplifying and giving them a more concrete appearance, attempting to fix them in place, taking "snapshots" that constantly need to be "touched up" (because something in the "picture" has moved). If the reasoning is anything like correct, it raises the provocative question: how much is our view of a relatively stable and predictable world a conceptual imposition?

\section{Concepts and conceptual spaces in motion}

So the conclusion should be that concepts are always in motion, jostling each other around, but not as mисh motion as the world they reflect: that is, they slow the motion down without ever stopping it. This follows naturally if one views concepts holistically, as part of a highly intertangled conceptual framework that is constantly being updated - as I have suggested one should do; rather than (as per Fodor's account) independent atoms bearing no relation to each other but only to the "external" world. All one's experiences to date - along with all the experiences one reads or hears about from others (i.e., experiences second hand) - are brought to bear (in whatever often highly indirect way) on the concepts one is applying in the present context and the reshaping of those concepts in their application: which is to say that all one's conceptually mediated experiences to date perturb one's present perspective, and conceptual agency is all about perspective (viewing the world one conceptually mediated way, and not another, where no one perspective is privileged above all others). ${ }^{33}$

At the same time that concepts discretize the world, imposing a degree of stability onto its continuous motion, they do the same thing to themselves. That is to say that our concepts, as and when

\footnotetext{
${ }^{33}$ This is not, of course, to deny that many perspectives are not useful or simply (for practical purposes) wrong, because they fail to reflect the world and one's interactions with it suitably. One can believe the world is flat, but that mean that one can treat it as such under all circumstances, without unfortunate consequences following! (This is not is not to open any discussion into the ontological status of truth, which is - it goes without saying - beyond the scope of this paper.) My thanks to Blay Whitby for private discussions on this point.
} 
we reflect on them - when we form concepts of our concepts - are themselves reifications, simplifying themselves, giving themselves a more concrete appearance, attempting to fix themselves in place. Again, it seems logical that they should be one thing when we are simply getting on with using them, quite another when we stop to look at them: $c f$. Michel Polanyi's (1958) distinction between focal and subsidiary awareness, itself evocative of a much earlier discussion from Heidegger on hammers (1978, p. 98).

Just as we can, and do, form concepts of our concepts: our concept of our concept of a dog ("how would I describe a dog?"), our concept of our concept of democracy (“what is democracy?"), our concept of a concept itself ("what does it mean to have a notion of whatever?"); so, too, we can form concepts of our concepts of our concepts. ${ }^{34}$ Quickly, however, we need to stop. Why? ... Because the concepts become too abstract, too far removed from their origins: an endlessly receding series of reflections, each level distorting the "image" a little more so that the point of departure might get lost entirely (Figure 3).

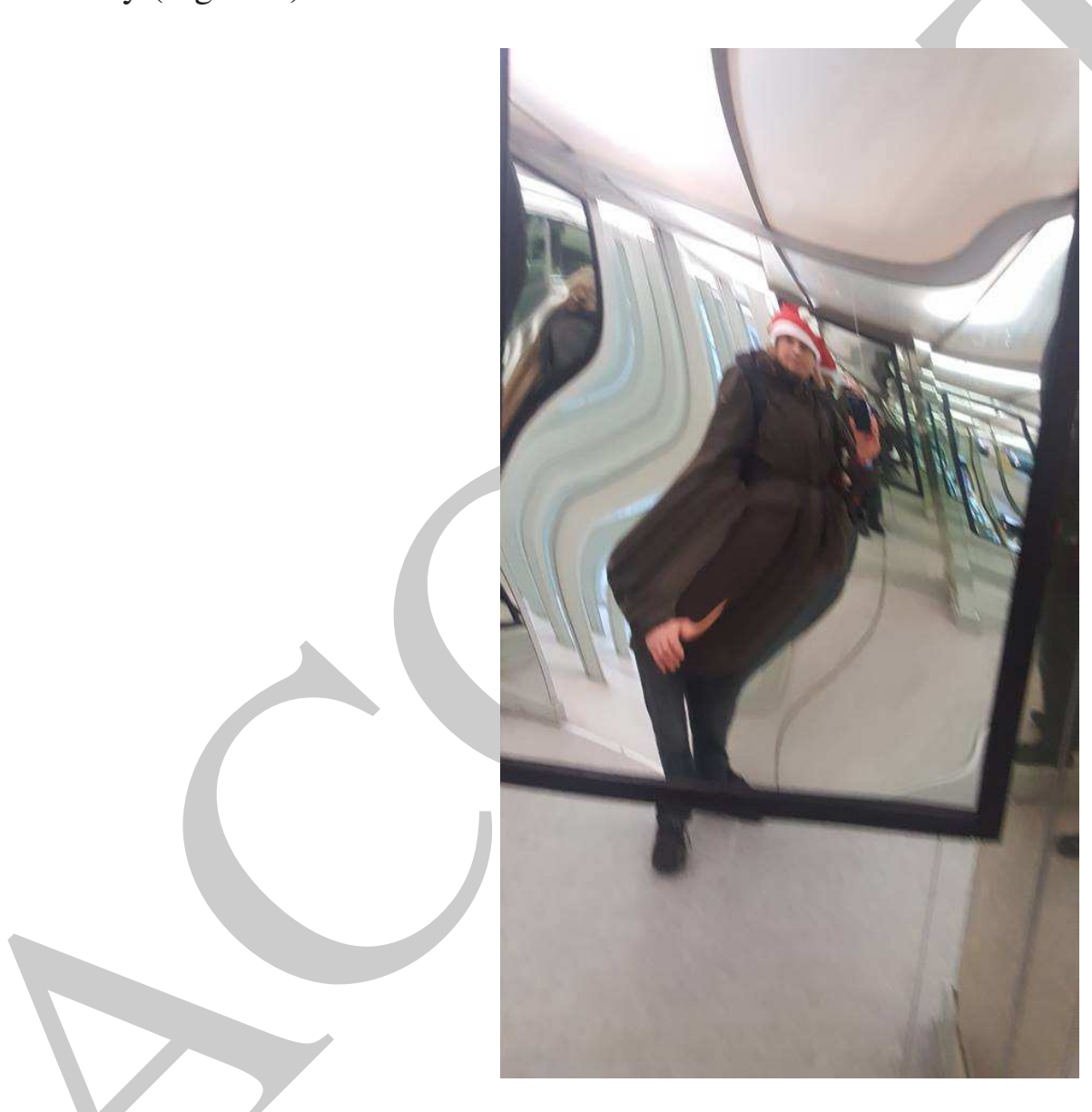

Figure 3: The author in a hall of mirrors. (Self-portrait.)

\footnotetext{
${ }^{34}$ Nothing about direction of flow - bottom-up vs. top-down - should be implied. Indeed, it is one of the standing claims of UCST that nearly all mature concept formation is a product of both bottom-up (unconsciously/preconsciously association-driven) and top-down (reflectively/intellectually driven) processes.
} 
The more abstract ("higher order", concepts of concepts of...), the more relatively stable the concepts become ${ }^{35}$ at the gain of generalizability but the loss, at least in most cases, ${ }^{36}$ of some corresponding degree of applicability to the world. Meanwhile the less abstract ("lower order", concepts of non-concepts), the more dynamic the concepts become, the less generalizable but the closer (seemingly) to the physical world. ${ }^{37}$

Of course a theory of concepts - such as Conceptual Spaces Theory, the Unified Conceptual Space Theory, Proxytypes Theory, or Informational Atomism - is itself a higher-order conceptual entity well along that continuum of abstraction and so should not be taken to be too true to the "real" nature of concepts, whatever that may be (besides, to some substantive degree, dynamic). Instead, one should look for particular theories of concepts to be useful in some contexts and not in others, applicable to some questions but not others ${ }^{38}$ : never truly universal. ${ }^{39}$ The moral of the story is that one should choose the conceptual tool - or theoretical framework - most appropriate to the task at hand as judged by apparent adherence to the reality of that task and explanatory productivity.

\section{Consequences theoretical and practical}

If concepts are in a state of continuous if incremental motion, what is the conceptual fallout? First, theorists working with models of conceptual frameworks (or, as the area is often if misleadingly referred to in cognitive science, knowledge representation ${ }^{40}$ ) need to take account of time in a much more active way: building a time dimension into the model; building models that change over time and move, with some apparently degree of autonomy; building conceptual spaces that change and adapt; thinking less in terms of, say, stable mind maps and more in terms of GPS navigation devices; the map created by these devices is updated on the fly: if the driver misses a turn, the directions immediately and silently change as though nothing had happened. If one is building models of moral agency and the moral frameworks possessed by purported moral agents - such as "intelligent" autonomous artefacts, as I discuss in (Parthemore \& Whitby, 2014, 2013, 2012) (see also e.g. Nyholm, 2017) - then one needs to treat that moral agency and those moral frameworks as moving targets. Meanwhile, the very

\footnotetext{
$35 \ldots$ Which is not to say that they cannot change - even (on occasion) change quickly! When they do change though it tends to represent a more radical departure than changes in our more concrete concepts: the analogue to Thomas Kuhn's (1990; 1970) talk of paradigm shifts.

${ }^{36}$ One's concept of what a concept itself is - or, if you will, a "notion" or an "idea" or a "thought" - is a necessary place holder but little more, until something more concrete is attached to it.

${ }^{37}$ Compare one's concept of an animal with one's concept of a bear with one's concept of a particular bear: say, the bear that chased you down the trail last summer.

${ }^{38}$ For example, much of the application of Conceptual Spaces Theory to date has been in the field of robotics; see e.g. (Chella et al., 2004, 2008).

39 ... Though some, again, may turn out not to be so useful or simply wrong.

${ }^{40}$ Whether all forms of conceptual understanding can usefully be described as "knowledge" is up for debate; but I hope already to have given readers reason to question the unqualified description of conceptual understandings as "representational".
} 
theories of concepts or knowledge that they are working from need to be not just open to change but actively seen as evolving entities: works in process. Often, both in publications and particularly in grant applications, one finds a great deal of emphasis on the goal, with what might be seen as exaggerated claims to providing the final, "correct" answer. As John Stewart so eloquently describes in (1995), there is no obvious reason to expect to find one final, "correct" answer for most phenomena of sufficient complexity.

The consequences are not only abstract and theoretical. Researchers need to "do" AI and to build AI systems in a radically new way. Conceptual Spaces Theory is already part of a broader movement, well represented in the enactive community, toward rejecting both good old-fashioned AI (GOFAI), with its strongly rationalist bent and its focus on top-down-driven symbolic approaches (including so-called physical symbol systems: see e.g. Newell, 1980); and connectionism, with its strongly bottom-up association-based approach (including "pure" artificial neural networks with no local but only distributed representations, and the like). Rather than arguing over whether anything needs to be built ("hard wired") into the system to begin with - whether it can start with a truly "blank slate" 41 - the question becomes, what is the minimum amount that must be built in to achieve maximum flexibility of response to the environment, maximum capacity for learning/adapting, and minimum overfitting? With regard to Conceptual Spaces Theory in particular, robots need to be built less with fully fledged conceptual spaces built in (see e.g. Chella et al., 2008) and more with minimally partitioned spaces (Parthemore, 2014a, p. 173) (2) $^{4}$ that the robot then develops: that is to say, everything the robot does should perturb, and so force an an update of, its conceptual spaces in their entirety; its unified space should be in a state of constant flux.

If self-driving cars are truly to be our collaborative partners rather than fully autonomous agents (Nyholm \& Smids, 2017) - which might be undesirable on both practical grounds (it's unclear whether artifacts can be autonomous in the strongest sense; many, including Jordan Zlatev (2002; 2001), have given reasons to think that might not be possible ${ }^{43}$ ) and ethical ones (what if the vehicle comes to the "wrong" conclusion, from the passengers' point of view?) - then one should build them to update themselves and their conceptually structured understanding 44 of their environment continuously - and sensibly! - in interaction with their driving partners and environment (in, needless to say, as flexible

\footnotetext{
${ }^{41}$ Arguably one of the key problems with GOFAI systems is not that knowledge is built in from the start but just how much gets built in: i.e., so much as to constrain severely its capacity to develop "cognitively".

${ }^{42}$ The core argument from that paper is that conceptual agents are born, not with any innate concepts, but with certain innate protoconcepts: in particular, protoconcepts for "object", "happening", and "property" that partition the subsequent unified space and force more or less all concepts into one of these broad proto-categories. We cannot make sense of the world and ourselves within that world except in terms of (concrete and abstract) objects, (concrete and abstract) happenings, and properties of both; it truly is inconceivable to imagine dividing the world along different lines.

${ }^{43}$ Clearly, treating an agent as fully autonomous when it's not risks dangerous consequences, as described in (Parthemore \& Whitby, 2014).

${ }^{44}$ Perhaps, the reader suggests, their understanding is structured in some other way than concepts - perhaps, but then the burden is on the reader to explain how, in a way that falls outside the dominion of concepts as they are defined here. Otherwise, concepts are simply going by a different name. Whatever form that structuring takes, it will presumably still need to be systematic and productive; otherwise, it will fail to generalize appropriately.
} 
but transparent a way as possible: e.g., through being open to a suitable degree of interrogation). The same applies to robots and other forms of automation in the workplace, at least if one wishes the remaining human workers to view the systems as partners rather than competitors (Danaher, 2017) and reduce the risk of costly lawsuits when something goes wrong because the situation was not anticipated by the system designers who hard-wired everything in. That is, the system's capacity to learn must be both robust and, in important if hard to specify ways, human-like; and that requires, at minimum, having a mind (or "mind") in motion.

Finally, are the claims made in this chapter empirically testable? Yes and no. They are, in the main, metaphysical in nature: by which I mean, they concern our axioms or starting assumptions. Like other metaphysical claims, they are only open to indirect empirical testing: an accumulation of circumstantial evidence, if you will, as opposed to any kind of proof. In (Parthemore, 2015) I lay out a detailed plan for empirical testing of CST and UCST, on the argument that, if CST/UCST-based mindmapping software benchmarks better than traditional mind-mapping software on such key factors as

- readability of maps between subjects,

- continued readability of maps over time (between subjects, and with the same subject),

- clarity of maps to experts in the domain, ${ }^{45}$

- speed and apparent accuracy of task completion,

- ease of using and declared comfort with the provided tools ${ }^{46}$ (as judged by post-experimental questionnaires/interviews), etc.

... Then one has good circumstantial evidence in favour of CST/UCST. Contrarily, if it benchmarks more poorly then parts of the underlying theory are either missing or wrong, or the cognitive theory behind traditional mind-mapping software really is superior. Beyond that, the question, ultimately, is whether one can explain empirical observations better - and, say, build better robots! - if one assumes that concepts change, and keep changing, and must keep changing, in the ways I describe.

\section{Conclusions}

With the exception of Fodor, most philosophers, psychologists, and cognitive scientists allow that concepts can change. The majority would probably allow that concepts, to function as concepts, must be open to change - certainly if the world they are meant to reflect changes, which it seems that it

\footnotetext{
${ }^{45}$ All three of these are notorious problems with traditional mind maps, for all of the miraculous claims made on them (see e.g. Sharples, 1999, also Parthemore 2011, ch. 8).

46 ...Especially given the additional restrictions imposed by the software; one of the standard complaints against traditional mind-mapping software is that it's massively underconstrained: users can throw down links anywhere and connect them with nearly any sort of arcs.
} 
often if not indeed continuously does. This chapter makes the far stronger and controversial claim that, when we are not looking at our concepts but simply applying them - that is, when considering them more practically and concretely, rather than abstractly - they should be understood as in a state of constant motion themselves. The apparent non-motion of concepts is - taken at face value - at best an incomplete story. What concepts do is to simplify and abstract away from the world at the same time they assist the conceptual agent to be flexible in responding to its environment. They do the same thing to themselves, whether one is talking concepts of concepts or theories of concepts or simply thoughts about thoughts: fixing themselves in place, giving themselves a more concrete, most stable appearance. Viewing concepts in this way, one is inclined not just to build more dynamic models of higher-level cognition but to view static snapshots of such cognition in a new light: as "images" that, if we riffle through them quickly, we can start to perceive the motion that we cannot - due to limitations of perspective - view directly. The individual snapshots are not the conceptual spaces just as, on reflection, the particular immediate application of a concept is not the concept. The movie, not the stills: that is where our conceptual spaces best may be seen as residing.

What I have not discussed, of course, is all the forms that conceptual change can take. Can a taxonomy of forms of change be provided; and, if it can, will it prove useful? How much depends on the weights on various quality dimensions, and how much are these weights assigned (as suggested by CST) or emergent (as UCST implies)? Just what happens when dimensions are added or removed, or when entire conceptual substructures collapse? In any case, conceptual spaces theory, in all its forms, offers rich ways for analyzing that change. ${ }^{47}$

\section{References}

Allen, C. (1999). Animal concepts revisited: The use of self-monitoring as an empirical approach. Erkenntnis, 51(1), 33-40.

Chella, A., Coradeschi, S., Frixione, M., \& Saffioti, A. (2004). Perceptual anchoring via conceptual spaces. In Proceedings of the AAAI-04 Workshop on Anchoring Symbols to Sensor Data (pp. 4045). Menlo Park, California: AAAI Press.

Chella, A., Frixione, M., \& Gaglio, S. (2008). A cognitive architecture for robot self-consciousness. Artificial Intelligence in Medicine, 44(2), 147-154.

Chrisley, R. \& Parthemore, J. (2007). Synthetic phenomenology: Exploiting embodiment to specify the non-conceptual content of visual experience. Journal of Consciousness Studies, 14(7), 44-58.

Danaher, J. (2017). Will life be worth living in a world without work? Science and Engineering Ethics, 23(1), 41-64.

\footnotetext{
${ }^{47} \mathrm{My}$ thanks to an anonymous reviewer for this point.
} 
Ellis, B. (2005). Physical realism. Ratio, 18(4), 371-384.

Fodor, J. A. (1998). Concepts: Where Cognitive Science Went Wrong. Oxford: Clarendon Press.

Gallagher, S. (2007). Phenomenological approaches to consciousness. In M. Velmans \& S. Schneider (Eds.), The Blackwell Companion to Consciousness chapter Phenomenological approaches to consciousness., (pp. 686-696). John Wiley.

Gallese, V. \& Lakoff, G. (2005). The brain's concepts: The role of the sensory-motor system in conceptual knowledge. Cognitive Neuropsychology, 22(3-4), 455-479.

Gärdenfors, P. (2004). Conceptual Spaces: The Geometry of Thought. Bradford Books. First published 2000.

Gärdenfors, P. \& Williams, M.-A. (2001). Reasoning about categories in conceptual spaces. In Proceedings of the Fourteenth International Joint Conference of Artificial Intelligence (pp. 385-392).: Morgan Kaufmann.

Harnad, S. (1990a). Introduction: Psychophysical and cognitive aspects of cognitive perception: A critical overview. In S. Harnad (Ed.), Categorical Perception: The Groundwork of Cognition (pp. 1-25). Cambridge University Press. First publication 1987.

Harnad, S. (1990b). The symbol grounding problem. Physica D: Nonlinear Phenomena, 42(3), 335346.

Harvey, I. (1992). Untimed and misrepresented: Connectionism and the computer metaphor (CSRP 245). http://www.sussex.ac.uk/Users/inmanh/harvey92untimed.pdf. University of Sussex (UK) Cognitive Science Research Papers (CSRP) series.

Heidegger, M. (1978). Being and Time. Wiley-Blackwell. First published in 1927 as "Sein und Zeit". Hofstadter, D. (2000). Gödel, Escher, Bach: An Eternal Golden Braid. Penguin. Twentieth anniversary edition.

Kuhn, T. (1970). The Structure of Scientific Revolutions. Chicago: University of Chicago Press.

Kuhn, T. (1990). The road since Structure. In PSA: Proceedings of the Biennial Meeting of the Philosophy of Science Association, volume 2 of 1990 (pp. 3-13).

Laurence, S. \& Margolis, E. (1999). Concepts and cognitive science. In E. Margolis \& S. Laurence (Eds.), Concepts: Core Readings chapter 1, (pp. 3-81). Cambridge, Massachusetts: MIT Press.

Newell, A. (1980). Physical symbol systems. Cognitive Science, 4(2), 135-183. 
Newen, A. \& Bartels, A. (2007). Animal minds and the possession of concepts. Philosophical Psychology, 20(3), 283-308.

Nyholm, S. (2017). Attributing agency to automated systems: Reflections on human-robot collaborations and responsibility-loci. Science and Engineering Ethics, (pp. 1-19).

Nyholm, S. \& Smids, J. (2017). Automated cars meet human drivers: Responsible human-robot coordination and the ethics of mixed traffic. Under review.

Parthemore, J. (2011). Concepts Enacted: Confronting the Obstacles and Paradoxes Inherent in Pursuing a Scientific Understanding of the Building Blocks of Human Thought. PhD thesis, University of Sussex, Falmer, Brighton, UK. Available from http://www.sussex.ac.uk/Users/jep25/papers/thesis/thesis-a4.pdf.

Parthemore, J. (2013). The unified conceptual space theory: An enactive theory of concepts. Adaptive Behavior, 21, 168-177.

Parthemore, J. (2014a). The case for protoconcepts: Why concepts, language, and protolanguage all need protoconcepts. Theoria et Historia Scientiarum, 11, 159-178.

Parthemore, J. (2014b). Conceptual change and development on multiple time scales: From incremental evolution to origins. Sign System Studies, 42, 193-218.

Parthemore, J. (2014c). Contemporary Sensorimotor Theory, volume 15 of Studies in Applied Philosophy, Epistemology and Rational Ethics, chapter From a sensorimotor to a sensorimotor++ account of embodied conceptual cognition, (pp. 137-158). Springer: London.

Parthemore, J. (2015). Specification of the unified conceptual space, for purposes of empirical investigation. In P. Gärdenfors \& F. Zenker (Eds.), Applications of Conceptual Spaces: The Case for Geometric Knowledge Representation (pp. 223-244). Springer.

Parthemore, J. (2017). Consciousness, semiosis, and the unbinding problem. Language \& Cognition, $54,36-46$.

Parthemore, J. \& Whitby, B. (2012). Moral agency, moral responsibility, and artefacts. In D. J. Gunkel, J. J. Bryson, \& S. Torrance (Eds.), The Machine Question: AI, Ethics and Moral Responsibility (pp. 8-16).: Society for the Study of Artificial Intelligence and Simulation of Behaviour (AISB). Available online from http://events.cs.bham.ac.uk/turing12/proceedings/14.pdf.

Parthemore, J. \& Whitby, B. (2013). When is any agent a moral agent?: Reflections on machine consciousness and moral agency. International Journal of Machine Consciousness, 5(2), 105-129. 
Parthemore, J. \& Whitby, B. (2014). Moral agency, moral responsibility, and artifacts: What existing artifacts fail to achieve (and why), and why they, nevertheless, can (and do!) make moral claims upon us. International Journal of Machine Consciousness, 6(2), 1-21.

Polanyi, M. (1958). Personal Knowledge: Towards a Post-Critical Philosophy. University of Chicago Press.

Prinz, J. (2004). Furnishing the Mind: Concepts and Their Perceptual Basis. Cambridge, Massachusetts, USA: MIT Press.

Quine, W. V. (1969). Natural kinds. In N. Rescher (Ed.), Essays in Honor of Carl G. Hempel: A Tribute on the Occasion of His Sixty-Fifth Birthday (pp. 5-23). Springer.

Rosch, E. (1975). Family resemblances: Studies in the internal structure of categories. Cognitive Psychology, 7, 573-605.

Rosch, E. (1999). Principles of categorization. In E. Margolis \& S. Laurence (Eds.), Concepts: Core Readings chapter 8, (pp. 189-206). Cambridge, Massachusetts, USA: MIT Press.

Sharples, M. (1999). How We Write: An Account of Writing as Creative Design. London: Routledge.

Stewart, J. (1995). Cognition = life: Implications for higher-level cognition. Behavioural Processes, $35(1-3), 311-326$.

Torey, Z. (2009). The Crucible of Consciousness: An Integrated Theory of Mind and Brain. MIT Press.

Woodfield, A. (1994). Do your concepts develop? In C. Hookway \& D. Peterson (Eds.), Philosophy and Cognitive Science (pp. 41-67). Cambridge University Press.

Zlatev, J. (2001). The epigenesis of meaning in human beings, and possibly in robots. Minds and Machines, 11, 155-195.

Zlatev, J. (2002). Meaning = life (+ culture). Evolution of Communication, 4(2), 253-296. 